\title{
1. The jurisprudential structure of environmental law
}

\author{
Douglas Fisher
}

\section{INTRODUCTION $^{1}$}

A legal system traditionally comprises a set of protectable rights and a correlative set of enforceable duties together with a range of institutional processes for their recognition, creation, implementation, compliance and enforcement. Such a system operates within the framework of the values and norms acceptable to the society which it serves. These arrangements manifest themselves in the form of rules that perform a range of different functions and disclose a variety of characteristics. Here are three examples. First, on the one hand there is the substantive right to own and to use land and the procedural right to vindicate this right in a court, while on the other hand there is the duty imposed on all persons not to interfere with or harm this right and supported by the procedural right to ensure compliance with this duty. Second, on the one hand there is the administrative right conferred on a public institution to make a decision affecting an individual, while on the other hand there is the duty imposed on the public institution to make the decision according to the relevant legal rules and supported by the procedural right of the individual to ensure compliance with these legal rules. Third, on the one hand there is the substantive right of the individual not to be assaulted, injured or damaged, while on the other hand there is the duty imposed on all persons not to assault, injure or damage an individual and supported by the procedural right of the individual and, in certain circumstances, of the state to ensure compliance with these rules.

Traditionally, these rules-based arrangements have been designed to protect the interests of the individual vis-à-vis those of other individuals and, more recently, to advance the broader interests of the society of which the individuals are a part. Over the last few decades, the broader interests advanced and protected by the law have expanded to include the public interest in how the natural resources of the environment are managed and how the environment is protected. This has introduced into the legal system at all levels - international, regional and national - not 
only new approaches to governance but also distinctive paradigms of governance. Accordingly, the context within which the rules have effect has become as important as the formal text - a treaty, a constitution, a statute or a judicial decision - within which they are expressed. Arguably, an innovative jurisprudential structure has begun to emerge in response to these ideological and doctrinal developments.

\section{THE DOCTRINAL DILEMMAS FACING ENVIRONMENTAL LAW}

The watershed of contemporary environmental law has often been taken to be the acceptance by the international community of the values incorporated in the Stockholm Declaration of 1972. Although it is an international instrument, it recognises the inherent relationship between individuals within the community and the states of which these communities are a part. Articles 1 and 21 acknowledge - at least by implication - this relationship. Article 1 recognises three specific fundamental rights of man 'in an environment of a quality that permits a life of dignity and well-being' and at the same time 'a solemn responsibility to protect and improve the environment for present and future generations'. Consistently with this from a structural perspective, article 21 recognises the sovereign right of states 'to exploit their own resources' and at the same time 'the responsibility to ensure' that damage is not caused to the environment beyond their territorial boundaries. There could be no clearer acknowledgment of the relationship between rights and responsibilities in relation to states and individuals. The emerging arrangements for environmental governance are an example of this relationship but they reveal a much more complex matrix of relationships.

The provenance of the Stockholm Declaration as a statement of principles declared at an international conference of nation states indicates that its provisions, while not strictly binding as a matter of law, represent the values favoured by the international community and the contexts in which they are intended to have effect. Articles 1 and 21 talk about rights and responsibilities at a structurally normative level. Multilateral environmental agreements similarly formulate rights and responsibilities at a structurally normative level. For example, article 2 of the Geneva Convention on Long-Range Transboundary Air Pollution 1979 states, first, that 'the contracting parties ... are determined to protect man and his environment against air pollution'. This is an expression of an intention linked to a value. Article 2, however, goes on to state, second, that parties 'shall endeavour to limit and, as far as 
possible, gradually reduce and prevent air pollution'. This is structurally different. It is an obligation to endeavour to achieve a stated objective. Although it is formulated as an obligation in a legal instrument, it probably does not constitute an enforceable obligation. Nevertheless it is part of the normative context within which the obligation has effect. Thus norms, rights and obligations perform different but not independent functions within these sets of arrangements. Again the question is their relationship.

Similar issues arise in relation to national arrangements for environmental governance. Section 2 of the National Environmental Management Act 1998 of South Africa states the principles that apply to the administration of the Act. Section 2(3) states: 'Development must be socially, environmentally and economically sustainable'. This is an obligation imposed not on any particular person. It is owed erga omnes. Its capacity to be enforced is perhaps unclear at this stage but its normative force is quite clear. Section 2(4)(o) is similarly structured as a normative rather than as a strictly legal obligation. It states:

The environment is held in public trust for the people, the beneficial use of environmental resources must serve the public interest and the environment must be protected as the people's common heritage.

These provisions are not only to assist in the performance of the range of functions created by the Act but also to guide the interpretation of the Act. These examples indicate that, both internationally and nationally, the normative and legal arrangements for environmental governance are interdependent and that the range of rights and responsibilities associated with them are equally dependent on each other. In practice this means that the interpretation, the application and the implementation of an instrument for environmental governance are a response to its status, structure, form and language.

\section{THE FUNCTIONS OF RIGHTS AND OBLIGATIONS IN ENVIRONMENTAL LAW}

It may be useful to put these perspectives into their jurisprudential context. A right recognised by international or national law may perform a range of different functions. A right may be formulated as a normative value - to freedom or to a healthy environment. Alternatively a right may be operational or administrative - to engage in a particular activity or to permit a person to engage in a particular activity, for example, to exploit 
resources, to use land for a particular purpose, to extract water from a particular source or to mine for specific minerals. The first is usually described as a right, while the second is usually described as a power. Then there are responsibilities. A responsibility is a general description of an obligation to engage in or not to engage in a particular activity. An example of the former is to take measures to reduce greenhouse gas emissions, to conserve biodiversity or to protect the environment. Examples of the latter are not to cause pollution, not to harm the environment and not to injure or damage the interests of a group of persons or of a particular person. A right formulated as a normative value remains in common parlance a right - usually a human right but increasingly as an environmental right. Powers and responsibilities - obligations or duties are described respectively in this chapter as rules of competence and rules of limitation.

It has been suggested that rules of competence and rules of limitation have effect within the wider framework of the normative values that are part of the overall system of environmental governance. The part played by these rules is critical. Rules of competence enable decisions to be made and describe what can be done in these circumstances:

- In the exercise of a right of sovereignty in the case of a state

- In the exercise of a right of property in the case of an individual or a private or public institution within a state including the state itself

- In the exercise of a right of administration by a public institution within a state.

The exercise of these rights is subject to a range of rules of limitation. There are in particular four:

- Strategic rules

- Regulatory rules

- Liability rules

- Market rules.

These have been described in these words:

Strategic rules point out the substantive direction of decision-making and of operational activity. Regulatory rules describe what cannot be done and what can be done through the involvement of the executive branch. Liability rules describe what can be done and what cannot be done in accordance with clearly stated and defined sets of rights and duties. Market rules provide for the administration of existing markets or the creation of new markets when 
economic instruments of this kind are seen to be a way of managing the environment. ${ }^{2}$

The rules of environmental law are both reactive and proactive in nature. Traditionally, legal rules have been reactive: determining what has happened in the past and deciding whether a rule has been breached and a liability incurred. Essentially these are liability rules. Here is an example. Has the person in question caused pollution of the waters of the river or caused the damage sustained by the injured party? The sanction may be civil or criminal. Although the sanction may look to the future an injunction, a fine or imprisonment - the initial stage of these proceedings is reactive.

Then there are proactive rules. Much of environmental law is now concerned with affording access to the resources of the environment and with protecting the environment. Although the private sector plays a part in these arrangements, for the most part these functions are performed by the public sector. The matters to be determined include:

- Should mining be permitted?

- Should land be reserved from development?

- For what purposes should land be used?

- How should biodiversity be conserved?

- How should this element of the environment be protected?

Significantly, the word 'should' is used. It connotes an element of discretion in addressing these issues and points to what should be the future outcome of the process. This is a proactive approach in the sense that it looks to the future rather than the past. The result, depending on the evidence and how it is analysed, may be the approval of the request and hence the grant of an interest in the resource or it may be the protection of an element of the environment. New rights and obligations have been created by this process and they have been created by the application of strategic rules.

The provisions - usually statutory - designed to protect the environment have mostly been regulatory in nature. The controlled activity is prohibited without an administrative grant of approval. The regulatory process of approval is governed by rules that are either substantive or methodological or both. In this way the rules explain not only what the objective or the outcome of the approval process is intended to achieve strategic rules - but also how the decision is to be made - methodological rules. A failure to comply with a strategic rule may in certain circumstances be justiciable. A failure to comply with a methodological 
rule will almost certainly be justiciable. Thus all involved parties - those engaging in activities impacting on the environment, those proposing to engage in activities likely to impact on the environment and those determining whether to grant administrative approval to such activities are subject to the relevant rules of law.

The policy objectives of the public sector are able to be achieved not only by these strategic, regulatory and liability rules but also by the use of economic instruments such as financial incentives or disincentives. The use of economic instruments places the responsibility for deciding what to do and how to do it upon the entrepreneur rather than upon the public sector as is the case with regulation. This is the most significant distinction between these two sets of arrangements - regulatory instruments and economic instruments.

The use of economic instruments, however, is not an example of a laissez-faire approach. Markets do not operate in a legal vacuum. Their operation depends upon rules of competence - a right of property and a right to enter into a contract - and upon rules of limitation such as those dealing with contractual, tortious or delictual liability and even liability under taxation rules. In addition, the operation of markets is sometimes regulated by sets of strategic and liability rules created by legislation. Environmental governance overall is thus a combination in all respects of strategic, regulatory, liability and market rules. Each set of rules plays an important but distinctive part in the overall system. Significantly, in theory and in practice they frequently operate in tandem with each other.

\section{THE EVOLUTION OF POLYCENTRIC GOVERNANCE}

To return to the fundamental values underpinning the system of environmental governance and implemented - at least in theory - by these sets of rules. Environmental law has a long history but not with that nomenclature:

- Medieval regimes of building regulation

- Nineteenth-century regimes for pollution control

- Establishment of national parks at the beginning of the twentieth century

- More sophisticated land use planning arrangements during the twentieth century

- Air and water pollution control during the second half of the twentieth century 
- The emphasis on the protection and improvement of the environment after the Stockholm Declaration.

These developments created a very fragmented and sectoral approach to environmental governance. The Stockholm Declaration provided the opportunity for a new approach. It emerged over the next 20 years in the shape of sustainability. Whatever it means in practical and operational terms and whatever its status as a matter of law, it is now the fundamental concept upon which the system of governance is based. It embraces these three dimensions - the economic, the social and the ecological - but each in the context of development. Development is a proactive notion - whether it is the development of the economy or of the society. But the economic, social and ecological dimensions operate to limit the way in which the notion of development operates. Perhaps in these words:

If a development is to satisfy the standard of ecologically sustainable development, then it must satisfy these three conditions. It must be sustainable in terms of the long-term and continuous use of the resource itself. It must be sustainable in terms of the long-term integrity and stability of the human resources that comprise the society in question. And it must be sustainable in terms of the ecological integrity of the environment out of which the resource is taken. ${ }^{3}$

If this is a credible analysis, it is a major challenge for all parties involved in environmental governance: nation states, legislatures, executive governments, judicial institutions, corporate institutions, nongovernment organisations and individual members of the community. A critical element is the simple idea of integration - not only of process and procedure but also of substance. There is one and only one intended outcome - sustainable development. The approach is neither anthropocentric (a focus on humans), nor ecocentric (a focus on nature), nor monocentric (a focus on one specific issue) but polycentric. This connotes a new conception of decision-making. There are fundamentally two challenges:

- The complex methodology of decision-making in environmental governance

- The substantive content of the notion of sustainable development.

The nature of polycentricity has been described in these words: 
The range of interests affected, the complexity of the issues and the interdependence of the issues means that decision-making involves a polycentric problem. A polycentric problem involves a complex network of relationships, with interacting points of influence. Each decision made communicates itself to other centres of decision, changing the conditions, so that a new basis must be found for the next decision. ${ }^{4}$

Against this background it is now relevant to review the way the jurisprudential structure of environmental law is revealed by the text of a range of international and national instruments and by their interpretation and application by judicial institutions.

\section{INTERNATIONAL PERSPECTIVES}

The United Nations Convention on the Law of the Sea 1982 provides for the governance by coastal states of the natural resources - living and non-living - of their exclusive economic zones. The first proposition in article 193 confers upon states 'the sovereign right to exploit their natural resources'. This is a rule of competence. The exercise of this right is regulated by a series of rules of limitation related to the objective of the optimum utilisation of these resources and the determination of the allowable catch. These are essentially strategic and regulatory rules. There is a generally formulated obligation in article 192: 'States have the obligation to protect and preserve the marine environment'.

This obligation is supported by the obligation in article 194(1) to take all measures necessary to reduce and control pollution of the marine environment and by the obligation in article 194(2) to take all measures necessary to ensure that damage by pollution is not caused to other states and their environment. Neither the right to exploit nor the obligation to protect is absolute. Their relationship is governed by the second proposition in article 193. In its entirety it provides:

States have the sovereign right to exploit their natural resources pursuant to their environmental policies and in accordance with their duty to protect and preserve the marine environment.

There is thus the juxtaposition of a rule of competence and a rule of limitation. The Convention - in the context of sustainable development discloses arrangements for the conservation - sustainable use - of the living resources of the sea as well as the protection of the marine environment itself. 
Article 2 of the Vienna Convention for the Protection of the Ozone Layer 1985 is structured in a way reflective of article 194 of the United Nations Convention on the Law of the Sea 1982. Thus:

The parties shall take all appropriate measures in accordance with the provisions of this Convention and of those protocols to which they are a party to protect human health and the environment against adverse effects resulting or likely to result from human activities which modify or are likely to modify the ozone layer.

The obligation to take measures - to an extent discretionary in nature - is linked to a strategic rule: the objective of protection. The Montreal Protocol 1987 to the Vienna Convention is structurally different. The rules of limitation in the Protocol are regulatory rather than strategic. The standards incorporated in the regulatory rules are stated to be the levels of consumption and production of controlled substances by each state. According to article $2 \mathrm{~A}(1)$ each state is required to ensure that for the relevant period its calculated level of consumption of the controlled substance does not exceed its calculated level of consumption in the year of commencement of these arrangements. It is a regulatory rule rather than a strategic rule because of the imposition of quantitative limitations.

The approach adopted by the United Nations Convention on the Law of the Non-navigational Uses of International Watercourses 1997 is again different. More than one state has - by definition - an interest in how international watercourses are managed. There is accordingly an obligation in article 8 to cooperate:

Watercourse states shall cooperate on the basis of sovereign equality, territorial integrity, mutual benefit and good faith in order to attain optimal utilization and adequate protection of an international watercourse.

This recognises the complementarity of rules of competence - sovereignty - and rules of limitation - utilisation and protection. This anticipates the notion of sustainable development. This notion is further reflected in the fundamental principle set out in article 5(1):

Watercourse states shall in their respective territories utilize an international watercourse in an equitable and reasonable manner. In particular an international watercourse shall be used and developed by watercourse states with a view to attaining optimal and sustainable utilization thereof and benefits therefrom, taking into account the interests of the watercourse states concerned, consistent with adequate protection of the watercourse. 
The first sentence states an obligation coupled with the relevant standard. This comes close to its formulation as a liability rule in the sense that a failure to comply with the standard may lead to a determination of liability. The second sentence states an obligation linked to a strategic rule - attaining optimal and sustainable utilisation - coupled with a methodological rule - taking the stated interests into account. The standards stated are clear:

- Equitable and reasonable

- Optimal and sustainable

- Adequate.

These are relatively subjective standards. It is likely, however, that in particular sets of circumstances they will be interpreted and applied in the context of the strategic and liability rules in the Convention. For example, what is an equitable use in the context of optimal utilization and what is adequate protection of the watercourse are determined from the perspective of all states. In any event, the general direction of these arrangements is sustainable use.

\section{CONSTITUTIONAL PERSPECTIVES}

It has become increasingly common for constitutions to include provisions about the environment. Article 11 of the Constitution of the State of Illinois in the United States is an interesting example. Section 1 of article 11 states: 'The public policy of the state and the duty of each person is to provide and maintain a healthful environment for the benefit of this and future generations'. Clearly, this is not only a statement of public policy but also the imposition of a duty on all persons. It seems to have been assumed that the provision is not enforceable - at least in relation to the public policy - because it goes on to indicate that legislation is required 'for the implementation and enforcement of this public policy'. Section 2 states that 'each person has the right to a healthy environment'. This similarly requires legislation to enable it to be enforced. On the face of it, therefore, the policy, the duty and the right are unenforceable unless supported by relevant statutory provisions. A court is unlikely to proceed in the absence of legislation. Nevertheless, article 11 clearly states the normative framework within which the state is expected to perform its statutory functions.

Not all courts are limited in this way. One example is India. There is no fundamental right to an environment of a particular quality in the 
Constitution of India. However, article 21 confers a fundamental right to life and article 32 confers a fundamental right to invite the Supreme Court to enforce this right. Articles 48-A and 51-A address the quality of the environment. The directive principles of state policy acknowledge the function of the state and the duty of every citizen in protecting and improving the environment. These provisions in the Constitution together with the developing rules and principles of international law - in particular the importance of sustainable development - led the Supreme Court to provide remedies for protection of the environment and to recognise the existence of a right to a healthy environment. Thus:

It is now an accepted social principle that all human beings have a fundamental right to a healthy environment, commensurate with their wellbeing, coupled with a corresponding duty of ensuring that resources are conserved and preserved in such a way that present as well as future generations are aware of them equally. ${ }^{5}$

Although described as a 'social' principle, the right to a healthy environment is couched in legal as well as normative language and supported by the international and constitutional sources relied on by the Supreme Court. Accordingly it has perhaps been transformed into a legal principle and a legal rule.

The Supreme Court of Costa Rica has been equally creative. The Political Constitution of Costa Rica includes provisions to this effect:

- Human life is inviolable

- Every individual has the right to a healthy and ecologically balanced environment

- The state guarantees this right.

In this way a right to life and a right in relation to the environment are brought together. The Supreme Court has noted that the improvement of the quality of life is the main objective of development: 'The latter must however be linked to the environment so that it is harmonious and sustainable'. ${ }^{6}$ In addition, 'environmental quality is a fundamental condition of the quality of life'. However, there is a wider normative perspective that is relevant:

Even more important is to understand that although man has the right to use the environment for his development, he also has a duty to protect and preserve it for the use of future generations. This is not a great novelty, it is no more than conveying in this specific context the principle against injury. This is well established in the common law (derecho comun), according to 
which the lawful exercise of a right finds two limitations: on the one hand the rights of others and, on the other hand, reasonableness in the exercise and the positive use of the right. $^{7}$

This approach comes close to acknowledging the existence of liability rules in the context of damage to the environment - based on the rules of the common law and no doubt of the civil law. There are, accordingly, on the one hand rules of competence and on the other hand rules of limitation. The criterion accepted by the common law is reasonableness: a concept inherently flexible and responsive to circumstances and one not unknown in international law.

These judicial comments are important because the concept of providing a remedy for an injury has been extended beyond an injury sustained by a person to an injury sustained by the environment. Importantly, the notion of an injury sustained by the environment is juristically linked to the concept that the quality of life is dependent upon the quality of the environment. This represents a complex web of relationships between humans and the environment, between rules of competence and rules of limitation, between human rights and environmental rights, and between constitutional rights and common law or civil law rights - all set in the context of sustainable development.

\section{STATUTORY PERSPECTIVES}

The arrangements enacted by legislatures in many jurisdictions reveal examples of strategic, regulatory and liability rules. Strategic and regulatory rules are largely the province of the public sector. Often they are supported by liability rules. There is an interesting example of liability rules as the principal mechanism for achieving their objectives. The US Comprehensive Environmental Response, Compensation and Liability Act (CERCLA) creates a liability regime in two sets of circumstances. Here is one: the person responsible for the release or a threatened release of a hazardous substance is liable for the costs of removal or the costs of remedial action incurred by the US government or other agencies and for any other necessary costs of response incurred by other persons. ${ }^{8}$ Here is the other: where there is injury to, destruction of or loss of natural resources resulting from the release or a threatened release of a hazardous substance, a liability arises to pay damages. ${ }^{9}$ For this purpose natural resources include wildlife, biota, air and water. ${ }^{10}$ Significantly this liability is owed to the US government and other prescribed agencies. ${ }^{11}$ In this respect the President of the United States is required to act on 
behalf of the public as trustee of the resources to enable the recovery of these damages. ${ }^{12}$ This liability regime comprises a set of rules of limitation. It is for the potentially liable persons - not the public sector to take action to prevent the release or threatened release of a hazardous substance. But this is supported by a rule of competence - the power and perhaps the duty of the President to enforce these rules ${ }^{13}$ and through the judicial system if necessary.

The Resource Management Act of New Zealand is a combination of strategic, regulatory, methodological and liability rules. A range of activities is prohibited without authorisation - the foundation of regulation. These include the use of land, the use of water and the discharge of substances impacting on the environment. This regulatory system is directed at the achievement of the purpose of the Act. According to section 5 this is to promote the sustainable management of natural resources. The lengthy definition of sustainable management brings together the functions of the use, development and protection of natural and physical resources in the context of their conservation and preservation and the protection of the environment.

The Act explains the methodology according to which the purpose of the Act is to be achieved. There is an obligation to recognise and provide for the matters of national importance stated in section 6 . These include:

- The preservation of the natural character of the coastal environment

- The protection of outstanding natural features and landscapes

- The protection of historic heritage.

Particularly important is the inclusion in section 6 of the relationship of Maori and their culture and traditions with their ancestral lands, water, sites, waahi tapu and other taonga. Section 7 imposes an obligation to have particular regard to a number of factors. These are both ecocentric and anthropocentric. The former includes the intrinsic values of ecosystems and the maintenance and enhancement of the quality of the environment; and the latter includes the efficiency of the end use of energy and the efficient use and development of natural and physical resources. Addressing both perspectives is the obligation to have particular regard to the effects of climate change.

The Environment Court of New Zealand has stressed the importance of the statutory methodology in making decisions under the Act and particularly the relationship between section 5 - the purpose - and sections 6 and 7 - the mandatory factors for consideration. These are all in Part 2 of the Act. The court explained the methodology in three succinct propositions. Here is the first: 
The cardinal and pivotal matter for us to bear in mind in weighing and evaluating the evidence and exercising our discretion is the Act's single purpose set out in $\mathrm{s} 5 .{ }^{14}$

Here is the second:

The remaining sections in Part 2, subsequent to s 5, inform and assist the purpose of the Act. We may accord such weight as we think fit to any competing consideration under Part 2, bearing in mind the purpose of the Act. These subsequent sections must not be allowed to obscure the sustainable management purpose of the Act. Rather, they should be approached as factors in the overall balancing exercise to be conducted by the court. ${ }^{15}$

Here is the third:

We thus propose to consider the relevant evidential matters, make decisions on the facts, and then apply a balancing and weighing process to determine what best achieves the single purpose of the Act. ${ }^{16}$

This is one judicial response to what has been described as a polycentric problem. The methodology is complex but the outcome is clear. Four features essential to solving this problem have emerged from this judicial analysis:

- The Act states its purpose

- It is one single purpose

- The objective is to achieve this single purpose

- To achieve this purpose the best alternative way of doing so must be selected.

The courts in the United States have on occasion directed their attention to the relationship between strategic and methodological rules. An early example is the Calvert Cliffs case which required an analysis of the US National Environmental Policy Act.

The Act contained a lengthy and detailed declaration of national environmental policy together with the imposition of a duty upon all agencies of the federal government to undertake an environmental impact assessment of all proposals for major federal actions significantly affecting the quality of the human environment. The judicial analysis of the Act began with this proposition: 'Our duty, in short, is to see that important legislative purposes, heralded in the halls of Congress, are not lost or misdirected in the vast hallways of the federal bureaucracy' ${ }^{17}$

The strategic - in this case the substantive - provisions were distinguished from the methodological - in this case the procedural - 
provisions. The substance of the Act was stated in the declaration of policy and the procedural provisions included the obligation to consider the environmental issues that had been identified by the required environmental impact assessment. The relationship between them was described in these words:

The general substantive policy of the Act is a flexible one. It leaves room for a responsible exercise of discretion and may not require particular substantive results in particular problematic instances. However, the Act also contains very important 'procedural' provisions - provisions which are designed to see that all federal agencies do in fact exercise the substantive discretion given to them. These provisions are not highly flexible. Indeed, they establish a strict standard of compliance. ${ }^{18}$

Although the strategic provisions stating the policy objectives of the Act were probably not taken to be enforceable, there was no doubt that the procedural provisions were enforceable. After a careful analysis of the Act as a whole, this was the conclusion:

Section102 ... mandates a particular sort of careful and informed decisionmaking process and creates judicially enforceable duties. The reviewing courts probably cannot reverse a substantive decision on its merits under section 101 unless it be shown that the actual balance of costs and benefits that was struck was arbitrary or clearly gave insufficient weight to environmental values. But if the decision was reached procedurally without individualised consideration and balancing of environmental factors - conducted fully and in good faith - it is the responsibility of the courts to reverse. ${ }^{19}$

It was to this extent that the court was able to ensure that 'important legislative purposes were not lost or misdirected' in the administration of the legislation. There would seem little doubt that the declaration of national environmental policy in the Act was a critical part of the methodology of decision-making required by the Act. The clearly stated 'legislative purposes' were almost mandatorily relevant.

The rules about environmental governance in Sweden are almost entirely contained in the Environmental Code of Sweden. The purpose of the Code stated in section 1 of chapter 1 is to promote sustainable development which will assure a healthy and sound environment for present and future generations. Sustainable development is underpinned by three concepts:

- Nature is worthy of protection

- Nature is capable of being modified and exploited 
- The exploitation of nature is conditional upon the wise management of natural resources.

The application of the Code requires a number of outcomes to be ensured. These include the protection of the environment and the preservation of biological diversity. The mechanisms for implementing the Code are traditional: for example, setting standards, managing protected areas, licensing prescribed activities, environmental impact assessment, liability regimes, and civil and criminal sanctions.

It is the range of obligations set out in chapter 2 of the Code and their substance that sets these arrangements apart from others. Some of the obligations are quite specific:

- To possess the knowledge necessary to protect human health and the environment

- To implement protective measures to protect the environment

- To select sites for land and water use so as to reduce damage to the environment

- To conserve raw materials and energy and to reuse and recycle them

- To avoid using chemical products or biological organisms involving risks to the environment.

The general obligation stated in section 1 of chapter 2 and linked to the more specific obligations is critical:

Persons who pursue an activity or take a measure, or intend to do so, shall show that the obligations arising out of this chapter have been complied with. This shall also apply to persons who have pursued activities that may have caused damage or detriment to the environment.

This applies to all measures that are not of negligible significance. It is important because it places the obligation upon the person who is pursuing an activity or intends to do so. It is not absolute. This is because, according to section 7 of chapter 2, these rules 'shall be applicable where compliance cannot be deemed unreasonable'. In other words, if there is no reason to justify non-compliance, there must be compliance.

The effect of these provisions has been summarised in this way:

Everybody must observe the rules of consideration, irrespective of any intervention on the part of a public authority. The rules lay down common requirements for all activities that involve a risk of harm to the environment. 
The party exercising the activity is, through the consideration of permits and similar procedures and supervision, liable to prove that the general rules of consideration of the Environmental Code are complied with. Thus, the burden of proof is reversed. ${ }^{20}$

The effectiveness of the Code is supported by the capacity of the Environmental Court of Sweden to ensure compliance. The strength of the Code is the extensive range of interrelated rules - strategic, regulatory and liability - designed to achieve the clearly stated purpose of sustainable development.

\section{CONCLUSION}

This review of international, constitutional and statutory instruments in a number of jurisdictions together with some examples of their judicial interpretation and application indicates that the arrangements for environmental governance disclose a number of common features. The standards set for behaviour and decision-making tend to be relatively general - fair, equitable, reasonable, appropriate, necessary, significant, rational, even wise. Much more significant have been the statements of value and of objectives or outcomes. These have become part not only of the regulatory systems that have been put in place but also of the liability regimes that exist alongside these regulatory systems or independently of them. These objectives have traditionally been sectoral - prevention of pollution, conservation of biodiversity, preservation of cultural heritage, protection of the environment - all set in the context of development of natural resources. The contemporary approach has become much more integrated through the influence of sustainable development.

The jurisprudential architecture has adapted to these changes. It has become almost common practice to incorporate values and fundamental norms in legal instruments; to give them effect through the formulation of strategic rules; to provide for their implementation directly by the public sector through sets of regulatory rules including methodological rules; and ultimately to ensure compliance with them by those engaged in operational activities through the automatic application of liability rules which in some cases complement the use of economic instruments supported by market rules. It has become a complex and interrelated web or matrix of rules of competence and rules of limitation. Rights and duties perform a range of different functions within this set of arrangements. Environmental governance seeks to move consistently in the direction of sustainable development - a controversial and structurally 
challenging vision for the future. The law has traditionally set standards of behaviour and of decision-making that are public knowledge. The community could therefore determine in advance whether or not their activities complied with the relevant rules. This remains so for environmental law. The processes of adjudication to determine whether there has been compliance with individual rights and duties are critical. But environmental law is now focused as much on promoting and protecting the wider public or community interest in how the resources of the environment are developed and how the environment is protected. The range of relevant interests has expanded exponentially and so has the range of relevant norms and rules. The following chapters review in detail many of these conceptual developments.

\section{NOTES}

1. See generally Fisher (2010) and Fisher (2013).

2. Fisher $(2014$, p. 11$)$.

3. Ibid. (p. 162).

4. Bulga case (2013, para.31).

5. Tirupathi case (2006, p. 322).

6. Mejia case (1993, p. 180).

7. Ibid. (pp. 180-181).

8. CERCLA, s.9607(a)(4)(A) and (B).

9. Ibid. s.9607(a)(4)(c) and 9607(f)(1).

10. Ibid. s.9601(16).

11. Ibid. s.9607(f)(1).

12. Ibid.

13. Ibid.

14. Genesis Power case (2005, p. 553).

15. Ibid. (p. 554).

16. Ibid. (p. 555).

17. Calvert Cliffs case (1971, p. 1111).

18. Ibid. (p. 1112).

19. Ibid. (p. 1115).

20. Silten (1999, p. 530).

\section{REFERENCES}

Fisher, D.E. (2010), 'A view of jurisprudential architecture for sustainable governance', Environmental Liability 3, 83-103.

Fisher, D.E. (2013), Legal Reasoning in Environmental Law (Cheltenham, Edward Elgar).

Fisher, D.E. (2014), Australian Environmental Law - Norms, Principles and Rules (Sydney, Lawbook Co. Thomson Reuters).

Silten M.S. (1999), 'Environmental Law in Sweden' in N.S.J. Koeman (ed.), Environmental Law in Europe (London, Kluwer). 


\section{INSTRUMENTS}

CERCLA: Comprehensive Environmental Response, Compensation and Liability Act Title 42 United States Code Annotated

Constitution of India

Constitution of the State of Illinois (United States)

Environmental Code of Sweden

Geneva Convention on Long-Range Transboundary Air Pollution: (1979) International Legal Materials 18, 1442.

Montreal Protocol: Montreal Protocol on Substances that Deplete the Ozone Layer: (1987) International Legal Materials 26, 1550.

National Environmental Management Act (South Africa)

Political Constitution of Costa Rica

Resource Management Act (New Zealand)

Stockholm Declaration: Declaration of the United Nations Conference on the Human Environment: (1972) International Legal Materials 11, 1416

United Nations Convention on the Law of the Non-navigational Uses of International Watercourses 1997: (1998) International Legal Materials 36, 700.

United Nations Convention on the Law of the Sea: (1982) International Legal Materials 21, 1261.

Vienna Convention for the Protection of the Ozone Layer 1985: (1987) International Legal Materials 26, 1529.

\section{CASES}

Bulga case: Bulga Mibrodale Progress Association Inc $v$ Minister for Planning and Infrastructue (2013) New South Wales Land and Environment Court 48.

Calvert Cliffs case: Calvert Cliffs Coordinating Committee v United States Atomic Energy Commission (1971) Federal Reporter 2nd Series 449, 1109.

Genesis Power case: Genesis Power Ltd v Franklin District Council (2005) New Zealand Resource Management Appeals 541.

Mejia Chaeon case: Mejia Chaeon v Ministry of Health (1993) International Environmental Law Reports 4, 131.

Tirupathi case: Intellectuals Forum Tirupathi v State of Andhra Pradesh (2006) Supreme Court Journal 2, 293. 